\title{
Los sermones del obispo Potamio de Lisboa
}

\author{
Juan Carlos Sánchez LeÓn *
}

\begin{abstract}
RESUMEN ABSTRACT
Este trabajo analiza los sermones De Lazaro y De martyrio Esaiae prophetae de Potamio, obispo de Lisboa en el siglo IV d.C. Las descripciones "tenebristas" de los

cuerpos de Lázaro e Isaías que

aparecen en estas obras, una "anatomía alucinante» que habla a la vista, al oído y al olfato, son probablemente un ejemplo muy personal de la simbiosis entre la medicina pagana y la teología cristiana que se produjo en el encuentro entre Hipocratismo y Cistianismo durante el imperio romano.

This piece of work analyse De Lazaro and De martyrio Esaiae prophetae Potamius' homilies, who was bishop in Lisbon in the 4th century. The "tenebrist" descriptions of Lazarus and Esaias' bodies, that emerge as these works like a "dazzlin anatomy" that speaks to the sense of sight, to the hearin and to the smell, set probably a very subjective exemple of the symbiosis that came about the pagan medicine and the Christian theology in the meeting between the Hippocratism and the Christianity during the Roman Empire.
\end{abstract}

La predicación tuvo que ser importante en el cristianismo de la Hispania antigua, pero sólo quedan escasos testimonios de la misma durante los siete primeros siglos de nuestra era. El primer vestigio de la homilética en Hispania -y uno de los más antiguos de la Europa latinacorresponde a los dos sermones conservados de Potamio, obispo de

* Universidad de Jaén. 
Lisboa hacia mediados del siglo Iv: el Tractatus de Lazaro y el Tractatus de martyrio Esaiae prophetae ${ }^{1}$. Según A. Wilmart, debemos a Potamio algunas páginas en latín que se encuentran entre las más curiosas de la antigua literatura cristiana, de un mal gusto, de una oscuridad y de una fatuidad pocas veces igualadas, un "léxico detestable" paradójicamente del primer escritor hispano en prosa del que se han conservado algunas obras ${ }^{2}$.

La escritura de Potamio ha sido considerada por la crítica como propia de un estilo «barroco español" ante litteram. Según G. Verd, el obispo de Lisboa es contorsionado en el período, rebuscado en el vocabulario, oscuro, ampuloso y extravagante, y tiene una gran imaginación descriptiva, viveza, realismo y hasta truculencia ${ }^{3}$. Para el P. Madoz, el estilo de Potamio ocupa un puesto solitario e inconfundible, caracterizado por su extravagante énfasis y singular rareza de estilo... su realismo colorista es genuinamente español, de la patria de Prudencio, de Ribera y de Valdés Leal, porque Potamio habla a los oídos, a los ojos, al olfato...con un léxico propio de poetas y clásicos paganos o inventa-

\footnotetext{
'A. WILMART, "Le De Lazaro de Potamius", Journal of Thelogical Studies 19 (1918) 289$304,289,297$

2 Sobre la predicación cristiana en la Hispania antigua, ver G. VERD, "La predicación patrística española", Estudios Clásicos 47 (1972) 227-251; F. J. Tovar, Tractatus, sermones atque homiliae. El cultivo del género literario del discurso homilético en la Hispania tardoantigua y visigoda, Universidad de Extremadura, 1994. Sobre la predicación cristiana antigua, ver en general E. MüL.HLENBERG-J. VAN OORT, hrg., Predigt in der Alten Kirche, Kampen, 1994; O. RotTMAnner, Predigten und unsprachen, München, 2 vols., 1902-1904; A. OLIVAR, La predicación cristiana antigua, Barcelona, Herder, 1991 ; E. Malaspina, Ars Temperans. Itinerari verso la communicazione polivalente nel mondo latino, Università di Genova, 1988; L. WILLS, «The Form of the Sermon in Hellenistic Judaism and Early Christianity", Harvard Theological Review 28 (1983) 337-350; W. VOGEL, "Biblical Exegesis and the Homily. Two decades in retrospect and prospect", Science de l'Esprit 34 (1982) 289-314; J. J. VON ALMEN, «Le prédicateur, témoin de l'Evangile", Irénikon 49 (1976) 453 485; G. ORLandoni, "La predicazione omilètica. Analisi sociologico del processo di comunicazione", Lateranum 43 (1977) 175-197; S. M. OberheLman, Rhetoric and Homiletics in Fourth-Century Christian Literature. Prose Rythm, Oratorial Style, and Preaching in the Works of Ambrose, Jerome and Augustine, American Classical Studies, Georgia, 1991; Ph. Rounlard, "Homélie", Catholicisme I, 1963, c. 829-831; J. K. COYLE, "The exercise of teaching in the postapostolic Church", Église et Théologie 15 (1984) 23-43; J. LECLERCQ, "Le sermon, acte liturgique», La Maison-Dieu 8 (1956) 27-37; Ch. MOHRMANn, «Praedicare-tractare-sermo. Essai sur la terminologie de la prédication paléochrétienne", in Id., Étude sur le latin des chrétiens II, Roma, 1961, 63-72; A. QUACQUARELLI, "Fondamenti della retorica classica e cristiana", Vetera Christianorum 25 (1988) 127-148; J. Chr. SalzMANn, Lehren und Ermahnen. Zur Geschichte des christlichen Wortgottesdienstes in den ersten drei Jahrhunderten, Tübingen, 1994; E. AuERBACH, Literary Lenguage and Its Public in Late Latin Antiquity and in the Middle Ages, New York, 1965; M. Banniard, Viva Voce. Communication écrite et communication orale du IVe au IXe siècle en Occident latin, Études Augustiniennes, París, 1992; R. MACMULLEN, "The preacher's audience», Journal of Theological Studies 40 (1989) 503-511.
}

3 G. VERD, 1972, 229 
do por él mismo ya que no se encuentran otros paralelos; Potamio usa un lenguaje gongorino, con contorsiones inextricables de estilo, hinchado, pomposo, de una grandilocuencia extravagante... es un estilista afectado y extravagante, atormentado colorista de torturas y realismos que hace pensar en una fusión extrema de Ribera y Valdés Leal ${ }^{4}$. Según Domínguez del $\mathrm{Val}$, la forma literaria de Potamio es única, inconfundible... su estilo pomposo, altisonante, estrafalario, hinchado, le hacen un escritor extravagante... abusa de las comparaciones y, cuando describe, lo hace con tal viveza y colorido que parece que se asiste a la escena ${ }^{5}$.

M. Meslin se pregunta por las causas de esta escritura heterodoxa del obispo de Lisboa: «habría que hacer un estudio de psicología literaria teniendo en cuenta un gusto cierto por lo horrible, las imágenes empleadas y las extrañas curiosidades de Potamio, a la vez que habría que estudiar la cultura literaria profana de este autor extraño vuelto curiosamente hacia lo horrible y lo bizarro" ${ }^{6}$. En este sentido, para J. Lorenzo, la singularidad de la lengua de Potamio se debe a la influencia del habla coloquial sobre la lengua escrita ${ }^{7}$. Por su parte, J. Scuderi Ruggeri opina que sería expresión de una cultura regional en los confines del Imperio, libre de la tradición clásica, que habría hecho posible una amplia intervención personal del autor en el campo literario; aunque no se puede precisar -afirma el autor- en qué medida la particular lengua del obispo de Lisboa (flexible en el estilo y particularmente realista en el vocabulario) depende de la evolución normal del latín en el Occidente hispano, de la tradición lingüística regional o de la voluntad innovadora del escritor. Scuderi Ruggeri señala el gusto acentuado de Potamio por las «imágenes de fisicidad sanguínea», una "anatomía alucinante» que aparece en sus dos sermones en las descripciones tenebristas del cadáver descompuesto de Lázaro y del cuerpo martirizado de Isaías ${ }^{8}$.

1. Para M. Simonetti, Potamio es una personalidad enigmática y desconcertante tanto en el plano humano como en el literario y en el doctrinal

\footnotetext{
4 J. Madoz, "Potamio de Lisboa», Revista Española de Teología 7 (1947) 79-109, 97, 100 , $102,105-106$

U. DOMinguez DEL VAL, "Potamio de Lisboa. Su ortodoxia y doctrina sobre la consustancialidad del Hijo", Ciudad de Dios 172 (1959) 237-258, 242-243

6 M. Meslin, Les Ariens d'Occident, París, 1967, 32 n. 4, y Revue d'Histoire des Religions 65 (1970) 133.

J. LORENZO, "Acercamiento a la sintaxis de Potamio", Emerita 46 (1978) 117-130.

8 J. SCUDERI RUGGIERI, «Considerazioni sul latino di Spagna del secolo IV», Cultura Neolatina 29 (1969) 126-158, esp. 133, 137, 141, 145, 147, 148
} 
9. Se desconocen las fechas de su nacimiento, de su ordenación episcopal y de su muerte; pero su implicación en la controversia arriana de mediados del siglo iv fue recogida por los escritores de la época (su nombre está asociado a los de Osio de Córdoba, Hilario de Poitiers, Atanasio de Alejandría, Febadio de Agen, Eusebio de Vercelli, Gregorio Bético, Ursacio y Valente). Para A. Wilmart, Potamio es obispo desde 345 o 347 según se deduce de su Epistula ad Athanasium ${ }^{10}$. Durante la primera fase de su episcopado, Potamio profesó la fe nicena, según testimonio no sospechoso del Libellus precum, panfleto que los presbíteros luciferianos hispanos Marcelino y Faustino presentaron al emperador Teodosio en 383-384 ${ }^{11}$. Sin embargo, el obispo de Lisboa se pasó a la herejía de Arrio en 355 y firmó la fórmula arriana del concilio de Sirmio de 357 . El obispo Febadio de Agen e Hilario de Poitiers lo consideran arriano hacia los años 357-358; el paso al arrianismo del obispo de Lisboa está también confirmado por un fragmento de la Epistula Athanasii ad Potamium episcopum, conservada por Alcuino en su Liber adversus haeresim Felicis, en la que el obispo de Alejandría acusa a Potamio de llamar a Cristo

M. SimonetTI, "La crisi arianna e l'inizio delia riflessione teologica in Spagna», Coloquio italo-spagnuolo sul tema: Hispania romana, Accademia nazionale dei Linzei, Roma, 1974, 127-147, 136-137. Sobre Potamio de Lisboa, la obra fundamental es A. MONTEs Moreira, Potamius de Lisbonne et la controverse arienne, Louvain, 1969, completada con el estudio «Le retour de Potamius de Lišbonne à l'orthodoxie nicéenne", Didaskalia 5 (1975) 303-354, a quien sigo aquí para los detalles biográficos. Ver, además de los trabajos ya citados, B. Altaner-E. Cuevas- U. Dominguez del Val, Patrología, Madrid, 1965, 5a ed., 352-353; M. Menéndez Pelayo, Historia de los heterodoxos españoles, Madrid, I, 1956, 124-127; M. SOTOMayor et al., Historia de la lglesia en España, I. La Iglesia en la España romana y visigoda, Madrid, 1979, 212 ss.; Z. GARCí VILLADA, Historia Eclesiástica de España, I, 2, Madrid, 1929, 45-52; A. Montes Morelra, "Potâmio e as origens do christianismo em Lisboa", Itinerarium 10 (1964) 461-487; Id., "O De Lazaro de Potâmio de Lisboa», Itinerarium 11 (1965) 19-53; ID., "Dois textos mariologicos de Potâmio de Lisboa", Itinerarium 13 (1967) 457-464; ID., "Potâmio de Lisboa e a controvérsia ariana", Repertorio de Historia de las Ciencias Eclesiásticas de España 1, Salamanca, 1967, 87-93; S. ALVAREZ, «El ritmo prosaico de Potamio de Lisboa ( $2^{2}$ mitad del S. IV)", Euphrosyne XVII, 1989, 265-276; ID., El ritmo prosaico hispano-latino (del siglo "ll a Isidoro de Sevilla). Historia y Antologia, Universidad de Santiago de Compostela, 1993, 61-65; U. DOMINGUEZ DEL VAL, «Herencia literaria de Padres y escritores españoles", Repertorio de Historia de las Ciencias Eclesiásticas de España, Salamanca, I, 1967, 5-6; J. MADOz, "Segundo decenio de estudios sobre patrística española (1941-1950)", Estudios Onienses, serie I, vol. V, Madrid, 1951, 57-60; ID., "Potamio", Enciclopedia Cattolica 9 (1952) 1847-1848; J. A. FERREIRA, "A queda de Potâmio, primeiro Bispo documentalmente conhecido de Lisboa (357-359), na heresia ariana, não tem base histórica accitável», Memórias da Academia das Ciências de Lisboa. Classe de Lettras III, Lisboa, 1938 (1940) 117-127; J. LORENZO, "Sobre un pasaje de Potamio», Helmantica 29 (1978) 165-171; ToVAR, 1994, 97-106; M. SIMONETTI, "Hilario de Poitiers y la crisis arriana en Occidente", Patrología III. La edad de oro de la literatura patrística latina, A. di Berardino dir., BAC, Madrid, 1993, 38 ss.

10 A. WILMART, 1918,284

11 Libellus precum IX, 32 ss. (CC 69, 368). Ver M. SOTOMAYOR, 1979, 212 ss.; M. MENÉNDEZ PelaYo, 1956, 102 SS., MADOZ, 1947, 81-82; WILMART, 1918, 258. 
"creatura" como sostenía Arrio ${ }^{12}$. En esta fase arrianizante de su episcopado, Potamio escribe tratados heréticos de los que sólo se conoce un extracto de una Epistula Potamii, transmitida por Febadio de Agen en el cap. $V$ de su Contra Arianos ${ }^{13}$. Según el comentario de Febadio, esta carta enseñaba la cristología del tipo Verbo-carne desde la perspectiva arriana: es decir, no poseyendo Cristo un alma humana y estando aseguradas las funciones de ésta por el Verbo, las debilidades psicológicas de Jesús (tristeza, temor, etc.), cuyo agente es el Verbo, demostrarían que el Hijo no es consustancial al Padre. Después del sínodo de Sirmio de 357 no hay información cierta sobre los actos de Potamio, pero se admite su retorno a la ortodoxia nicena poco después del concilio de Rímini en 359, en el que tomó parte. Su muerte debió producirse hacia 360 , en todo caso antes de 383-384, fecha en la que se escribe el Libellus precum.

Aunque Potamio no aparece mencionado en los catálogos de autores ilustres de Jerónimo, Gennadio o Isidoro de Sevilla, el obispo de Lisboa se vanagloria de haber tenido éxitos literarios. Lo cierto es que solamente perviven de su obra cuatro escritos, todos de carácter ortodoxo:

- una carta a san Atanasio, que forma parte de un vasto dossier antiarriano compuesto por los luciferianos de Hispania (Epistula Potamii ad Athanasium episcopum), redactada probablemente poco después del concilio de Rímini en 359 y de la vuelta del obispo de Lisboa a la ortodoxia nicena;

- una carta «Sobre la Substancia del Padre, y del Hijo, y del Espíritu Santo", encontrada entre las cartas de Jerónimo, escrita posiblemente poco después de la anterior (Epistula beati Iheronimi de substantia patris ac filii et spiritus sancti);

- dos breves sermones, uno sobre el martirio de Isaías, fragmentario (De martyrio Esaiae prophetae), el otro sobre la resurrección de Lázaro (De Lazaro), éste citado por san Aigustín en Contra lulianum 1, 6, 24, y en Contra secundam luliani responsionem opus imperfectum 6,7 , creyéndolo obra de Juan Crisóstomo ${ }^{14}$.

12 PL 101, col. 113.

13 PL 20, col. 15.

14 Epistula Potamii ad Athanasium episcopum = A. WILMART, "La lettre de Potamius à Saint Athanase", Revue Benedictine 30 (1913) 280-282; Epistola beati Iheronimi de substantia patris ac filii et spiritus sancti $=$ P.L. Suppl. 1 (vol. 222, París, 1958) cols. 202-216; De martyrio Esaiae prophetae = A.C. Custodio VEGA, Opuscula omnia Potamii episcopi Olisiponensis..., Scriptores ecclesiastici hispani-latini veteres fasc. 2, El Escorial, 1934, 35-36; DE LA.ZARO = A. WILMART, Journal of Theological Studies 19 (1918) 298-304. Ver los testimonios, transmisión manuscrita, ediciones, 
2. A. Wilmart reconstruye la transmisión de los sermones De Lazaro y De martyrio Esaiae en dos tradiciones latinas diferentes. Las obras han debido pasar de Hispania a Italia en la segunda mitad del siglo IV, probablemente a través del Norte de África (Zenón, obispo de Verona - muerto hacia 370-, las habría llevado de Mauritania a Italia hacia 360$)^{15}$. En la segunda década del siglo $V$, entre 415 y 421 , el sermón sobre Lázaro fue incluido en una colección latina de unas cuarenta homilías bajo el nombre de Juan Crisóstomo (muerto en 407), que un pelagiano, Aniano de Celada, acababa de traducir al griego. San Agustín, forzado en la controversia con los pelagianos a disputarse el patronazgo de Juan Crisóstomo, se procuró antes de 421 un ejemplar de esta colección latina recientemente interpolada en Italia, de la que tomó algunas citas, entre ellas una del De Lazaro de Potamio. Por otro lado, a comienzos de la Alta Edad Media, el sermón sobre Lázaro original del obispo de Lisboa, junto al sermón del martirio de Isaías, entraron a completar el corpus de las homilías del obispo Zenón de Verona, escritas tras 360 , corpus compilado después de su muerte hacia 370; las dos obras sólo fueron atribuidas al obispo de Lisboa por los hermanos Ballerini en $1739^{16}$.

En el De Lazaro, Potamio introduce su discurso aludiendo a las sensaciones que el relato de la resurrección de Lázaro provoca en el autor y remarcando el parentesco entre Lázaro y Jesús. Comienza con una larga digresión filosófica y antropológica sobre el cuerpo y la muerte recordando que, conforme al Libro del Génesis, Lázaro iba a convertirse con su muerte en lo que ya había sido (lutum scilicet, dum desinit esse quod erat forma vel fabula). Seguidamente, describe en términos extraordinariamente rea-

supervivencia y bibliografía de las obras de Potamio, en MADOz, 1947, 106-109. Las obras citadas de Agustin en PL 44, cols. 656-657, y 45, cols. 1512-1513, respectivamente, donde el sermón de Potamio aparece con el nombre de Homilia de Lazaro resuscitato (las citas de Agustín corresponden a las líneas 88-90 de la ed. Wilmart, p. 302). Sobre la identificación en detalle de las obras de Potamio, ver MONTES MOREIRA, 1969, 219-300.

15 El problema del origen africano de Zenón (A. BIGELMAIR, Zeno von Verona, Münster, 1904) se está reexaminando ahora desde la perspectiva más amplia de las relaciones e influencias entre la literatura cristiana de Átrica romana y la literatura cristiana de Italia septentrional en el siglo IV: V. BOCCARDI, "Quantum spiritaliter intelligi datur. L'esegesi di Zenone di Verona», Augustinianum 23 (1983) 453-485, 454. Ver C. Truzzl, Zeno, Gaudenzio e cromazio. Testi e contenuti della predicazione cristiana per le chiese di Verona, Brescia e Aquileia (360-410), Brescia, 1985; R. Lizzi. Vescovi e strutture ecclesiastiche nella città tardoantica (L'Italia Annonaria nel IV e V secolo d.C.) Biblioteca di Athenaeum 9, Como, 1989; L. PADOVESE, I/ pensiero etico-sociale di alcuni vescovi norditaliani del IV secolo, Roma, 1983.

6 WILMART, 1918, 292-295; ver MOntes Moreira, 1969, 246 ss. y MAdOz, 1947, 90 ss. La edición de los Ballerini en PL 8, cols. 1411 ss; ver especialmente "F. ZOLBEAU, Zenoniana. Recherches sur le texte et sur la tradition de Zénon de Vérone", Recherches Augustiniennes 20 (1985) 3-34; V. BOCCARDI, 1983, 453-485. Sobre el contenido de los sermones, sigo en general a MONTES MOREIRA, 1969, 254 ss.; ver también Tovar, 1994, 97 ss. y SCudeRt RugGIERI, 1969, 137-141. 
listas y pormenorizados la descomposición del cadáver Lázaro después de llevar sepultado cuatro días, aludiendo a la irreversibilidad de este proceso. El lector y/o el oyente asisten literalmente a la escena con todos sus sentidos, en particular la vista y el olfato: huelen el ambiente de hedor que infesta la comarca, contemplan la horrorosa disolución del cadáver:

«Yacía con el rictus de las mandíbulas caído, los dientes arrancados de la boca, la boca maloliente; porque, en efecto, creado de la miseria terrena, se desharía como una gleba podrida, y el triste sepulcro condenaría a los haces de nervios, junto con la masa del cuerpo, al pus miserable. Con los miembros contraídos, la oscura piel se distiende entre las costillas secas, que se pueden contar, y un chorro de líquido, que se desprende del remolino de las vísceras, convertido ya en una cloaca hedionda, se desliza, negro y azulado, por el fondo del cadáver. Ay, después de cuatro días y cuatro noches, ¿cómo iba a poder reanimar el cadáver aquellos ríos inmundos de hiel y humores que inundan la boca, aquellos respiraderos hediondos de los pulmones entre los miembros corrompidos? ¿Pues no es cierto que hasta la casta y hermosa rosa de hojas fragantes, que está tan preciosa en su propio perfume, si, por el contrario, es arrancada del rosal por la hoz del pulgar, empalidecería triste con lánguida muerte, hasta perder el color y el olor?" ${ }^{17}$.

Este fenómeno de la putrefacción, asegura Potamio, es provocado por la feroz batalla que libran los cuatro componentes del cuerpo humano: la tierra, el agua, el aire y el fuego. Según el obispo de Lisboa, las energías impetuosas y contrarias de estos elementos están dominadas y controladas en vida por el "auriga" autoritario y sabio del alma; pero con el "divorcio de la muerte" estalla una lucha encarnizada que conducirá a su mutua aniquilación final (idea que parece una reminiscencia platónica y que también comparte Tertuliano) ${ }^{18}$. Aunque Potamio se adhiere aquí a la

17 Traducción de G. VERD sobre PL 8, co: $1412=1972,229-230$. El pasaje completo de la disolución del cadáver de Lázaro en la ed. Wiln art es: Hic quippe, per graues tenebrarum globos et nigri horroris umbracula, hoc est per quatuor dierum circulos, succidua incrementi et decrementi uicissitudine renascentes, -octo, ut ita dixerim, cum caerulis noctibus dies-, pendulo mandibularum rictu, elisis in ore dentibus, foetido ore sic iacuit, uere quia de terrena labe confectus, putris gleba, marcesceret et neruorum traduces cum corporis qualitate miserabili tabo infelix sepultura damnaret. Contractis igitur membris inter ieiunas et numerabiles costas pellis tetra distenditur et humoris riuus qui de gurgite uiscerum relaxatur foetenti iam sentina per solum cadaueris teter et caeruleus labebatur. Heu, quando non poterat cadauer, quatuor diebus et quatuor noctibus, per totum oris feIlis et flemmatis flumina sentinarum, corruptis artubus foetentia, pulmonis spiramenta conflare? cum ipsa etiam rosa pudoris et uenustatis fraganti folio in suo sibimet parato balsamo, ut ita dixe. rim, pretiosior, contra si fuerit de rosario falce pollicis uellicata, marcenti morte tristis albescat, ita ut et colore fioris careat et odore (ed. WILMART, 299).

${ }_{18}$ Nemo ergo mirari debeat, si hominis, - quem spiritus, sapientiae sale conditum, redolenti aura seruauerat et ex caeli suauitate anima uiuacitate nectarea et balsami generositate melliflua rexerat, ne fieret diuortio recedentis spiritus lutea moles et pigra glebositas, caduca linea defunctorum repugnantibus fabricae qualitatibus-, corpus omne ad foetoris maculam sui de putredine 
doctrina de la composición tricotómica del hombre -corpus, anima, spiritussin explicar las relaciones existentes entre los dos últimos elementos, alma y espíritu, su antropología es dualista, como ha señalado Montes Moreira ${ }^{19}$. Esta combinación de términos antropológicos para expresar una antropología dualista no es rara, aparece ya en Pablo: «hombre interior», "espiritu», «alma, «mente» definen la parte no corpórea del hombre, mientras que «hombre exterior», "carne», "cuerpo», «miembros», «boca», "cara»y otras metáforas definen, a su vez, la parte corpórea del hombre ${ }^{20}$.

Tras la digresión antropológica, viene el relato del milagro. Jesús promete a las hermanas del difunto, Marta y María, resucitar a Lázaro si creen en él, y se reúne una gran turba de curiosos para asistir al prodigio (spectaculum servandam memoriae). Potamio se detiene ahora para describir el encuentro de Jesús con las hermanas de Lázaro y explicar el sentido profundo de las lágrimas de Cristo ante la tumba de Lázaro ${ }^{21}$. El relato del milagro sigue poco después: Lázaro resucita, manifestando el triunfo de Cristo, y se desenvuelve normalmente.

Potamio alude a la recuperación de Lázaro después de resucitar, insistiendo no como opina Tovar en cada una de las partes del cuerpo que al comienzo del discurso se iban descomponiendo (cabeza —mandíbulas, dientes, boca-, miembros, pulmones, entrañas, huesos - costillas-, nervios, líquidos -hiel, humores- = anatomía de la muerte), sino en los sentidos y funciones corporales que no menciona al principio del sermón (vista, oído, voz, movimiento de los miembros = anatomía de la vida) ${ }^{22}$.

relaxetur. Inde est quod, per distantiam rerum in unam glomerationem compacta, omnis membrorum natura torpescit. Recedente igitur anima quae corporis floriarium recolebat, tota materies liuenti gena in putredinem relaxatur et pro uoce cadaveris nigri fellis teter mortui foetor hauritur. Terra igitur humore frigore et calore composita corporis fabrica (quae quatuor partes semper sibimet re. pugnantes corpus criminum in procella subuertunt: calor frigus non amat et frigus calore torquetur, - contraria contrariis mancipantur - terra nimio humore uitiatur et humor de terra sordescit), his quadriformibus elementis in unum quadripartita mole constantibus, dissociato per diuortium mortis auriga qui quatuor istis partibus loca dederat, ne quisquam mobilitatem sui uehementibus tolleret, et dominante flagro diuisis in unum concordanti iunctura finibus agitabat, hae, inquam, quatuor partes, recedente anima, in globum corporis uiduati, excusso societatis auctore, miscentur (ed. Wilmart, 299-300).

19 Montes Moreira, 1969, 255, pero sobre todo ID., 1975, 348, con correcciones sobre la antropología de Potamio.

20 Ver R.H. Gundry, Soma in Biblical Theology. With emphasis on Pauline Anthropology, Cambridge University Press, 1976, 155-156. Ver también R. JEWETT, Paul's Anthropological Terms. A Study of their use in conflict settings, Leiden, 1971.

${ }^{21}$ Sobre la posible ambigüedad teológica desde el arrianismo del tema de las lágrimas de Cristo (Flebat Deus), ver MONTES MOREIRA, 1975, 327-328.

22 Mors vincitur, homo redditur, infernorum catenae franguntur, et post quatriduum Lazari lingua mouetur, manus officio praeparantur, oculi suis in orbibus currunt, uestigia gressibus explicantur, auribus renouatur auditus, acies dirigitur in parientes (ed. WILMART, 304); TOVAR, $1994,101$. 
Según Wilmart y Madoz, algunos de estos detalles del De Lazaro son tan precisos que podrían haber sido tomados de fuentes apócrifas, ya que Potamio gustaba de este tipo de literatura y conocía el apócrifo La Ascensión de Isaias; pero para Montes Moreira los detalles que indica Wilmart no figuran en los Evangelios apócrifos que se conocen y estos evangelios apenas hablan de la resurrección de Lázaro ${ }^{23}$. Potamio elabora su discurso sobre el texto evangélico Juan 11, 38-44 (teste evangelio apud loannem, dice), el único que menciona este milagro de Cristo. No hay que olvidar que cuando el De Lazaro entra en la colección de homilías de Juan Crisóstomo, to hace sin los detalles macabros sobre la putrefacción del cadáver de Lázaro y sin los pormenores estilísticos extravagantes ni las frases embrolladas de la digresión sobre el compuesto del cuerpo humano (líneas. 4-51 de la edición Wilmart). Por otro lado, para Madoz y Simonetti, existen numerosos contactos literarios entre Potamio y Tertuliano (fines del s. II-principios del III): el paralelismo de las metáforas y la presencia de conceptos trinitarios propios de Tertuliano testimonian la dependencia doctrinal y literaria de Potamio en estos campos ${ }^{24}$.

En el De martyrio Esaiae (fragmento de un sermón más amplio), Potamio relata el martirio del profeta Isaías, el cual, según una antigua tradición judía, había sido seccionado en dos con una sierra de madera por orden del rey Manasés (693-639 a.C.). Potamio afirma que Isaías fue acusado de blasfemia por su iabor profética y sometido a suplicio; Balkira, falso profeta, intentó en vano que renegara de su fe mientras Isaías estaba ensimismado en un éxtasis con el Espíritu Santo (también un prodigio, al igual que en el De Lazaro). El obispo de Lisboa, fiel a su estilo, detalla con pormenores las partes supliciadas del cuerpo del profeta, describiendo la progresión de la sierra desde la cabeza hasta las entrañas de una forma extraordinariamente viva y realista ${ }^{25}$. De la misma manera que en el $D e$ Lazaro el lector y/o el oyente veían y olían el cadáver putrefacto de Lázaro, en este sermón el lector y/o el oyente ven y oyen el aserramiento del cuerpo de Isaías, la lenta penetración de la sierra que parte en dos el

\footnotetext{
23 WILMART, 1918, 298 n. 1, que cita las líneas 5, 73 ss., 100, 114, 118-123 de su edición; Madoz, 1947, 95; Montes Moreira, 1969, 258-9. Sobre los Apócrifos, ver E. HenNECKE-W. SCHNEEMELCHER, Neutestamentliche Apokryphen, Tübingen, 2 vols., 1959-1964.

24 MAdOZ, 1947, 103-105; SIMONETTI, 1974, 136-137, basándose en el Adversus Praxeam (212-213) de Tertuliano; ver MonTEs MoreIRA, 1975, 324

25. Esaias... atroci feriate blasphemantium commota barbaries, sectum a capite duabus eum uiolento supplicio quasi offulis bifidauit, iussitque a capite per aures usque ad scapulas secari ceruicem : quasi parum fuerit si immanitate lymphatica martyrem dei acuto ense transfoderet, aut ipsa lamina insontes uiri per iugerum fidiculae saevientis per costas stridente ictu sulcaret; nisi in unum corpus duas offulas gemini paene cadaueris scissae carnis ruptura truculentus appeteret, et duas de aequalitate iuncturae quasi formulas exsecaret (ed. CUSTODIO VEGA, 35).
} 
cuerpo del profeta ${ }^{26}$. Seguidamente, Potamio dedica algunas líneas al trabajo del mago Bélias, hijo de Ezequías, el cual se libra a ciertos augurios sobre el cuerpo del profeta; quizá Potamio confunde a este personaje con el rey Manasés ${ }^{27}$.

La descripción anatómica del cadáver martirizado de Isaías sigue la misma pauta que la descripción del cadáver disuelto de Lázaro, es decir una anatomía de la muerte: cabeza (orejas, cabello, piel), sistema circulatorio (corazón, venas, sangre), entrañas, huesos (cerviz, omóplatos, costillas).

Hay que resaltar de este sermón la particularidad de que está dedicado a una especie de mártir del Antiguo Testamento (martyrem dei en palabras de Potamio) que, además, es torturado conforme a los martirios posevangélicos con una sierra, dato basado en un libro apócrifo; al mismo tiempo, Potamio considera el martirio de Isaías como anticipo de la pasión y resurrección de Cristo ${ }^{28}$. Para el martirio por aserramiento y la intervención de Bélias en el suplicio, Potamio se basa en el cap. $V$ de la obra apócrifa Ascensión de Isaías (sección Martirio de Isaias); la información sobre la causa del martirio (haber pregonado la venida de Cristo y reprobación del pueblo hebreo) proviene del mensaje fundamental de algunas visiones relatadas en otras secciones del apócrifo como el breve Apocalipsis (cap. III, 31 ss.) y la Visión de Isaías (caps. VI-XI) ${ }^{29}$. Sin embargo, hay algunas diferencias

2h Traducción sobre PL 8, col. 1416. El pasaje en la ed. Custodlo VEGA es: Cum in capite, hoc est, collectae sensualitatis umbilico serra uiam taceret, et stridore reciproco sulcos dentium duceret, labebatur, credo, lamina, dum dentes infigit, et per messem capillamenti, crassumque tegminis uelamentum, uel callosae glutinum cutis hebraeas capitis litteras textum uerticis mersit. 2. Mox se ut ad cubile cordis concinnamenti nisu sector sollicitus defixisset, fontis fluenta purpurei laxatis uenarum lapsibus, ne uenas uermiculatim pollice profanator intenderet, croceus se affatim imber infudit, ut tecta gurgite sanguinis uenarum pictura non tremeret, et quale esset illud unde uictus erubescere miraretur (ed. Custodio VEGA, 35-36).

${ }_{27}$ Sed Belias, filius Ezechiae, uir cruentus, et prodigus genealogiae, mathematicus, catabolicorum, fatidicorum, et pythonicorum antistes, intra loricam sacri pestoris fidei comitium, praedicationis politicae litterarum curiam requirebat. Ef licet iam esset membratim corporis diuisa possessio, interna proderet, abdita reuelaret, obscura porrigeret, et quale esset illud, unde uictus erubescere miraretur, ut persecutor infamis hominem dei dentibus discerperet alienis; propheta tamen egregius et illustris inter resupinatos sectores, et pendulos tamdiu immobili inconcussi corporis perdurauit statu, quamdiu duo esse incepererit, qui figuras gentium cum suo persecutore damanarent (ed. GUSTODIO VEGA, 36).

28 TOVAR, 1994, 101-102.

29 E. TISSERANT, Ascension d'isaïe. Traduction de la version éthiopienne avec des principales variantes des versions grecque, latines et slave. Introduction et notes, París, 1909, 128-132, con la traducción francesa del cap. V. Ver F. BAfDEAL, Le fivre de l'ascension du prophète Isaïe..., París, 1979 (Préface); A. AcERBI, L'Ascensione di Isaia. Cristologia e profetismo in Siria nei primi decenni del // secolo, Studia patristica Mediolanensia, Milan, Università Cattolica, 1989, 28-32 para el análisis detallado del martirio. Se trata de una obra compuesta de tres secciones: la primera, Martirio de Isaías, es de origen judio y fue redactada a fines del siglo I, como muy tarde; las otras dos, un breve apocalipsis y la Visión de Isaías, son de origen cristiano y han debido de ser compuestas a finales 
importantes entre el apócrifo y la obra de Potamio, especialmente el hecho de que mientras la Ascensión de Isaías omite la descripción anatómica pormenorizada del suplicio y relata en su lugar un diálogo entre Isaías y su acusador (el falso profeta Balkira, que trata de que Isaías reniegue de su fe), Potamio, en cambio, describe con todo lujo de detalles la progresión de la sierra a través del cuerpo del martirizado. Por otro lado, el apócrifo no habla para nada de las actividades mágicas de Bélias.

3. Para Tovar, desde el punto de vista literario, los dos sermones de Potamio tienen la misma estructuración del discurso, basada en el empleo del recurso retórico tradicional de la synkrisis, es decir, la contraposición de dos polos narrativos: la descripción anatómica del cadáver de Lázaro y la resurrección del mismo, y la descripción anatómica del cuerpo de Isaías en el momento del suplicio y el triunfo del mártir por ensimismamiento en el Espíritu Santo y por la comparación con la resurrección de Cristo ${ }^{30}$.

Según este autor, los sermones de Potamio no responden ni temática ni formalmente a la literatura homilética. Potamio se anticipa así a la práctica generalizada de la «paráfrasis» en la literatura cristiana y no influye en la configuración posterior de la homilética más parafrástica, la de los tractatus populares. El predominio del tema sobre el texto resulta ser una práctica retórica que la literatura homilética cristiana no seguirá, y de ahí la singularidad de la obra pionera y aislada de Potamio.

Así, para Tovar, los sermones de Potamio no se basan en ningún pasaje del Antiguo Testamento o de algún libro bíblico en verso y no siguen la exégesis propia del tractatus: "en el obispo de Lisboa se funde una marcada personalidad estilística con un recurso plenamente retórico, y no gramatical, la synkrisis; éste implica la existencia de una elaborada disposición, que responde a un intento no tanto de «reescribir» el «texto

del siglo 10 a mediados del siglo $1 ;$ la fusión de los tres escritos puede datarse poco después de la Visión de Isaías. Recientemente, A. AcERB considera este apócrifo como un texto globalmente cristiano, una relectura del Antiguo Testamento sobre bases exegéticas judaicas y cristianas, fruto de un grupo profético cristiano de Siria occidental en los primeros decenios del siglo il. La Ascensión de Isaías tuvo una difusión notable y varios autores cristianos lo utilizaron antes y después de Potamio (ver TISSERANT, 1909, 62 ss.). Según TISSERANT (1909, 65), Jerónimo habría atestiguado la difusión de este apócrifo en Hispania y Lusitania en un pasaje de su Comentarii in Isaiam (XVI, 64, 45 = PL 24, 622-623), pero para MONTES MOREIRA (1969, 290), Jerónimo evoca en este fragmento el desarrollo del gnosticismo y de otras herejías en estas regiones y no la propagación de la Ascensión de Isaías y del Apocalipsis de Elías. Ver A. ACERBI, Serra Lignea. Studi sulla fortuna della "Ascensione di Isaia", Roma, 1984.

30 Tovar, 1994, 105-106, con un buen análisis literario de los sermones, que sigo aquí; ver también Scuderi Ruggieri, 1969, 137-141. 
de referencia» cuanto de formular una oposición existente a priori en el mismo «texto de referencia». De esta forma, Potamio recrea desde perspectivas racionalistas el pasaje de la muerte de Lázaro, con el fin de generar un contraste con su resurrección...además el obispo de Lisboa equipara el sufrimiento de un personaje del Antiguo Testamento (Isaías) con una tradición martirial posterior...no se propone un texto para ejercitar la práctica gramatical propia de los tractatus, sino un tema para recoger una práctica retórica: "putrefacción frente a resurrección», "martirio del Antiguo Testamento frente a martirio del Nuevo Testamento"...

Finalmente, prosigue el autor, Potamio deja de lado la capacidad pedagógica de su discurso en favor de un ejercicio muy personal de estilo, de tonos «barrocos», por lo que sus sermones no están destinados a contribuir al acervo exegético de la literatura cristiana. Tovar propone, pues, considerar los sermones de Potamio como tractatus retóricos, declamationes cristianas o ejercicios sofísticos sobre pasajes de las Escrituras y de los apócrifos, más que homilías en el sentido estricto del término.

4. Sin embargo, los sermones de Potamio no son exclusivamente retóricos, tienen una particular capacidad pedagógica. Las descripciones anatómicas que aparecen en estas homilías son probablemente un ejemplo muy personal de la simbiosis que se produjo entre la medicina secular pagana y la teología cristiana en el encuentro entre Hipocratismo y cristianismo durante el Imperio.

Como opina O. Temkin, en un nivel amplio, la nueva doctrina necesitaba de la ciencia médica hipocrática para la elaboración de una antropología cristiana, una doctrina del hombre que aceptara aquellas partes útiles de la filosofía natural griega sin sacrificar las creencias cristianas, en especial la inmortalidad del alma y la resurrección de los cuerpos ${ }^{31}$. Pero la

31 O. TEMkIN, Hippocrates in a world of pagans and Christians, Johns Hopkins University Press, Baltimore-London, 1991, 133. Sobre la medicina antigua y el cristianismo ver, además, M.D. GRMEK dir., Histoire de la pensée médicale en Occident, vol. I, París, 1995; J. Scarborough, Roman Medicine, Ithaca, Comell University, 1969; Ch. SINGEF- E.A. UnDERwoOD, A short history of Medicine, Oxford Clarendon Press, 1962, $2^{\mathrm{a}}$ ed.; D. GOUREVITCH. Le Triangle hippocratique dans le monde gréco-romain: le malade, sa maladie et son medecin, Rome-Paris, 1983; G. PENSO, La medicina romana: l'arte di Esculapio nellantica Roma, 1985; T.S. BARTON, Power and knowledge: astrology, physiognomics and medicine under the Roman Empire, 1994; $\mathrm{CH}$. DE FiLIPPIS CAPPAl, Medici e medicina nell'antica Roma, 1992; L. EDELSTEIN, Ancient Medicine, Baltimore, 1967; A. Harnack, Die griechische Vebersetzung des Aplogeticus Tertulian's, Medicinisches aus der ältesten Kirchengeschichte, Leipzig, 1892; D. W. Amundsen, "Medicine and Faith in Early Christianity", Bulletin of the History of Medicine 56 (1982) 326-350; Id., "Medicine and Religion: Early Christianity through the Middle Ages", in Health/Medicine and the Faith Traditions, M.E. MARTY-K.L. VAux eds., Philadelphia, 1982, 93-131; ID., "Body, Soul and Phisician», en ID., Medicine, Society, and Faith in the Ancient and Medieval Worlds, The John Hopkins University Press, Baltimore-Londres, 1996, 1-29; G.F. 
utilidad de la medicina pagana (tanto para la curación del cuerpo como para la enseñanza práctica o la disputa teológica) no aseguró a la medicina hipocrática un lugar comparable al de la medicina cristiana del alma. Para los cristianos, el cuerpo era un problema. Por un lado, la carne era despreciada y sus deseos reprimidos; por otro, el cuerpo albergaba el alma y por esto merecía respeto. En el centro de la cuestión estaban el valor otorgado al cuerpo mortal, qué cuidado había que dar a este cuerpo en cuanto a la salud y a la enfermedad, y hasta dónde había que llegar en la mortificación de la carne.

La discusión teológica sobre la resurrección revela estas cuestiones centrales. Desde la perspectiva bíblica, el hombre está constituido como unidad de cuerpo y alma, de manera que el cuerpo puede ser animado y el alma puede expresarse en obediencia a Dios. Ambas partes de la constitución humana comparten la dignidad de la imagen divina. La muerte se define por la separación entre el alma y el cuerpo: éste continúa existiendo por un tiempo después de la muerte y después se degrada; aquélla continúa existiendo y, además, tiene conciencia ${ }^{32}$.

La doctrina cristiana de la muerte y la resurrección había sido fijada en la antropología paulina. En su respuesta a los Corintios (¿con qué cuerpo resucitarán los muertos?: I Cor. 15: 35), Pablo declaró que aunque el cuerpo natural es corruptible y está minado por el deshonor y la debilidad, se elevará en incorruptibilidad y en poder como cuerpo espiritual:

FERNGREN, "Early Christianity as a religion of healing", Bulletin of the History of Medicine 66 (1992) 1-15; V. NUTTON, "Murders and miracles: Lay attitudes towards medicine in classical anriquity", in R. POATER ed., Patients and Practitioners. Lay perceptions of medicine in pre-industrial society, Cambridge University Press, 1985, 23-53; R. ARBESMANN, «The Concept of 'Christus Medicus' in St. Augustine», Traditio 10 (1954) 1-28; A.S. PEASE, "Medical Allusions in the Works of St. Jerome", Harvard Studies in Classical Philology 25 (1914) 73-86; H. SCHIPPERGES, «Zur Tradition des 'Christus Medicus' im frühen Christentum und in der älteren Heilkunde", Arzt und Christ 11 (1965) 12-20; S. D'tRSAY, “Patristic medicine", Ann. Med. Hist. \& (1927) 364-378; ID., "Christian medicine and science in the third century», Journal of Religion 10 (1930) 515-544; H.C. KEE, Medicine, Miracle and Magic in New Testament Times, Cambridge University Press, 1986, trad. esp., Córdoba, 1992.

32 Ver GundRY, 1976, 159-160. Sobre el cuerpo en el cristianismo antiguo, ver la obra esencial de P. Brown, The Body and Society: Men, Women and Sexual Renunciation in Early Christianity, New York, Columbia Univesity Press, 1988; R.B. ONIANS, The Origins of European Thought about the Body, the Mind, the Soul, the World, Time and Fate, Cambridge University Press, 1951; M.R. MILES, Augustine on the Body, Montana, 1979; T.J. BAveL, «The Anthropology of Augustine", Louvain Studies 5 (1974) 34-47; A.H. ARMSTRONG, "Neoplatonic Valuations of Nature, Body and Intellect», Augustinian Studies 3 (1972) 35-59; P. FREDERIKSEN, "Beyond the body/soul dichotomy: Augustine on Paul against the Manichees and Pelagians", Recherches Augustiniennes 23 (1988) 87-114; P. COURCELLE, «Tradition platonicienne et traditions chrétiennes du corps-prison (Phédon 62 b; Cratyle 400 c)", Revue des Études Latines 43 (1965) 406443; E. MAsutTI, // problema del corpo in S. Agostino, Roma, 1989, esp. 62 ss. y cap. 2 ("Il rapporto anima-corpo"). 
«...la carne y la sangre no pueden poseer el reino de Dios, ni la corrupción poseerá esta herencia incorruptible...» (I Cor. 15: 50-53) ${ }^{33}$. Ireneo, en el siglo II, hizo de esta idea la piedra central de su argumento ortodoxo sobre la resurrección en Adversus haereses 5, 6, 1: lo que era imposible para la mera carne y sangre era posible para el «ser humano completo", formado a imagen de Dios, en el que el alma «que acepta el espíritu del Padre» está unida con la carne. Como remarca Temkin, esta idea no representa una continuación del debate sobre la posibilidad fisiológica de la resurrección, por lo que el valor supremo del alma inmortal y el dogma de la resurrección de los muertos no será cuestionado en las disputas teológicas de los tres primeros siglos; el cuerpo, en el mejor de los casos, será percibido como un compañero del alma, y en el peor, como un vehículo degradante ${ }^{34}$.

Sin embargo, para algunos autores cristianos del siglo IV, como Basilio de Cesarea (323-379), la ciencia del hombre, desde el punto de vista médico, consiste en conocer que éste ha sido hecho a imagen y semejanza de Dios (tema del Génesis de la imago Del). La definición que da Basilio de la medicina es hipocrática pero espiritual, un modelo para la curación del alma. Con todo, los cristianos deberían conocer las investigaciones médicas de los paganos: "Dado que no lo comprendemos, sin examinar nuestra propia constitución, ignoramos lo que somos y tampoco sabemos por qué somos. Nos despreocupamos de nosotros mismos, ignorando lo que está al alcance de nuestro conocimiento y las cosas más elementales que hay en nosotros. Se han consagrado mucha atención y muchos trabajos a nuestro cuerpo humano. Si consideras el arte de la medicina, verás cuántas cosas nos descubre sobre nuestro funcionamiento, cuántos conductos secretos ha

33 Sobre la diferencia paulina entre la corruptibilidad (en sentido material) y la corrupción (en sentido espiritual) del cuerpo tras el pecado original, en San Agustín, ver A.-M. LA BonNARDIËRE, Biblia Augustiniana. A.T. Le Livre de la Sagesse, París, 1970, 208 ss. Sobre la doctrina y la pastoral cristiana de la muerte en ios Padres de la Iglesia, ver J. DANiELOU, «La doctrine de la mort chez les Pères de l'Église", in Le mystère de la mort et sa célébration. Lex Orandi 12, París, 1951, 134-156; Morte e immortalità nella catechesi dei Padri del III-IV secolo, Roma, 1985, F.S. PAxton, Christianising Death. The Creation of a Ritual Process in Early Medieval Europe, Ithaca, $1990 ;$ E. REBILLARD, In Hora Mortis. Évolution de la pastorale chrétienne de la mort aux IVe et Ve siècles dans l'Occident latin, École Française de Rome, Rome, 1994; J.-A. FISCHER, Studien zum Todesgedanken in der alten Kirche. Die Beurteilung des natürlichen Todes in der Kirchlichen Literatur der ersten drei Jahrhunderte, München, 1959; J. PELIKAN, The Shape of Death. Life, Death and Immortality in the Early Fathers, London, 1962; D. SICARD, La liturgie de la mort dans l'Église latine, des origines à la réforme carolingienne, Liturgiewissenschaftliche Quellen und Forschungen 63, Münster, 1978; P.-A. FÉVRIER, "Le culte des morts dans les communautés chrétiennes durant le Ille siècle», Atti del IX Congresso internazionale di archeologia cristiana, Roma, 1977, I, 265 ss.

34 TEMKIN, 1991, 136. En la perspectiva cristiana, carne y cuerpo no son lo mismo: Mateo 26 , 41 opone el espíritu a la carne y considera que el cuerpo, más que carne, es un templo. 
encontrado en nuestra estructura interna a través de la disección, las uniones invisibles, el concierto del cuerpo para respirar, las vías del aliento vital, los vasos sanguíneos, la tracción respiratoria, la instalación de un foco de calor cerca del corazón, el movimiento continuo del aliento vital alrededor del corazón. Miles de observaciones sobre todo esto han desembocado en una ciencia de la que no tenemos experiencia, por no haber prestado atención a este dominio de la investigación y porque nadie se conoce a sí mismo. Tendemos a conocer el cielo mejor que a nosotros mismos. ¡No desprecies la maravilla que hay en ti!» 35 .

Los tratados médicos paganos de época imperial versan especialmente sobre las enfermedades y su tratamiento, es decir sobre la anatomía patológica; raramente sobre la anatomía descriptiva, como la obra básica Sobre los procedimientos anatómicos de Galeno (siglo ॥), que influirá decididamente en la medicina cristiana. Aparte del De medicina de Celso (siglo 1), que conjuga anatomía descriptiva, anatomía patológica e historia de la medicina y de la cirugía interesándose en todos los órganos, y del resumen de Vindicianus en el siglo IV, de los siglos IV y $\vee$ sólo pueden aprovecharse los tratados de ginecología para conocer el estudio de la forma y estructura de los elementos del cuerpo humano ${ }^{36}$.

Según Temkin, la teología cristiana, el simbolismo bíblico de la enfermedad y los ejemplos bíblicos de las enfermedades del alma transformaron la medicina pagana del alma en medicina espiritual. La medicina hipocrática retuvo en este proceso la función de proveer las analogías prácticas necesarias, y esta función fue vista desde el cristianismo como la

35. Basilio de Cesarea, De Structura Homini (In Hexaemeron X) 1-2, edición y traducción francesa de A. Smets-M. van Esbroeck, Sur l'origine de l'homme (Hom. X et XI de l'Hexaéméron, Sources Chrétiennes 160, París, 1970, 169. Ver A. BENITO y DuRÁN, «L'humanisme des homélies...attribuées à saint Basile», Diotima 7 (1979) 63-70, esp. 64; ID., “Filosofía de San Basilio Magno en las Homilías «In Hexaemeron», Atti del XII Concresso Internazionale di Filosofia (Venezia, 12-18 settembre 1958), Firenze, 1960, 21-30; Y. CouRTONNE, Saint Basile et l'hellenisme. Etude sur la rencontre de la pensée chrétienne avec la sagesse antique dans l'Hexaméron de Basile le Grand, París, 1934; P. Rousseau, Basil of Caesarea, California University Press, Berkeley, 1994.

36 Ver los autores romanos sobre anatomía, en J. ANDRE, Le vocabulaire latin de l'anatomie, París, Les Belles Lettres, 1991, 21 ss. Sobre la anatomía y fisiología antiguas, ver H. LEITNER, Bibliography to the Ancient Medical Authors, Stuttgart, 1973; G. SABBAH-P.P. CORSETTI-K.D. FISCHER, Bibliographie des textes médicaux latins. Antiquité et haut moyen âge, Publications de l'Université de Saint-Etienne, 1987; K.B. ROBERTS, The fabric of the body: European traditions of anatomical illustration, Oxford Clarendon Press, 1992; C. Singer, A short History of Anatomy and Phisiology from the Greeks to Harvey, New York, 1957; E. BENVENISTE, "Termes gréco-latins d'anatomie", Revue des Études Grecques 57 (1944) 7-40; F. SKodA, Médecine ancienne et métaphore: le vocabulaire de l'anatomie et de la pathologie en grec ancien, París, 1988; Ph. HEuzE, L'image du corps dans l'oeuvre de Virgile, 1982; F. CAPPONI, L'anatomia e la fisiologia di Plinio, Università di Genova, 1995. 
principal intención de Dios al otorgar esta ciencia al hombre. Al proveer una amplia variedad de analogías médicas prácticas, la medicina hipocrática se convirtió en una parte vital de la exégesis teológica y de la práctica pastoral cristianas ${ }^{37}$. Así, la medicina hipocrática como saber pagano se integró en el universo cristiano no sólo a través de la inclusión de la teoría médica en la exégesis teológica erudita, sino también a través de la teología popular de algunas homilías en las que las enseñanzas prácticas hipocráticas pasaron al pueblo ordinario. Como opina Amundsen, los $\mathrm{Pa}$ dres usaron analogías médicas en las que la teoría médica, la teoría de la causalidad natural o la descripción de técnicas médicas y/o quirúrgicas específicas empleadas en problemas médicos prácticos, proveyeron ricas comparaciones homiléticas ${ }^{38}$. Este es el caso de los sermones sobre los seis días de la creación de Genesis 1, el específico género literario cristiano del Hexameron: después del relato sacerdotal (Gen.1, 1-2, 4), el yahvista retoma la narración y describe el modelado del hombre ${ }^{39}$.

Filón de Alejandría, en su obra De opificio mundi, trazó el modelo de Hexameron para los exégetas posteriores siguiendo el plan de la Biblia ${ }^{40}$. La obra de Lactancio (ca. 260-ca. 330) es la primera en lengua latina de este género. Lactancio, filósofo y rétor pagano convertido al cristianismo, analizó en su tratado De opificio dei liber (303-305) la constitución física del hombre para mostrar la perfecta adaptación de los órganos a su fin. El De opificio es un tratado antropológico en el que Lactancio relata las maravillas que se encierran en el hombre para demostrar, en polémica con los epicúreos, la existencia de la Providencia y presentar al hombre como obra perfecta de Dios ${ }^{41}$. En este tratado, concebido como exégesis teoló-

37 TEMKIN, 1991, 176-177.

38 AMUNDSEN, 1982, 331.

39 Ver F. RobBins, The hexameral literature. A study of Greek and Latin commentaries on Genesis, Diss. Univ. Chicago, Chicago, 1912, que distingue seis etapas en la historia de la exégesis judía y cristiana del Hexameron: la filosofía griega y los antiguos comentarios del Génesis, Filón de Alejandría y los escritos judios, los primeros Hexameron antes de Basilio, Basilio, sus sucesores, San Agustín.

40 Eusebio de Cesarea, muerto en 339, menciona cuatro autores de un Hexameron antes de Orígenes, todos de fines del siglo 11: Rhodón, Cándido, Apión e Hipólito; por su parte, Teófilo de Antioquía, también a fines del siglo II, sigue de cerca la obra de Filón. En las dos homilías de Orígenes sobre el Génesis hay que buscar la fuente inmediata de las homilías de Basilio in Hexaemeron $X, X I$ que serán retomadas por Ambrosio como modelo. Ver SMETS - VAN ESBROECK, 1970, 95-97. La edición de Orígenes en L. Doutreleau-P. Henri de Laubac, Origène, Homélies sur la Genèse, Sources Chrétiennes 7, París, 1944, esp. 78-86.

4i L. Caecilii Firmiani Lactantii, De opificio dei liber, 3-64, ed. M. PERRIN, Lactance. L'ouvrage du dieu créateur, I-II, Sources Chrétiennes 213-214, París, 1974. Ver L. RossetTi, “ll De opificio Dei di Lattanzio e le sue fonti", Didaskaleion 6 (1928) 115-200; J. BRYCE, The Library of Lactantius, Harvard University Press, N.York-London, 1990, 208 ss. (The Human Body); P. MonAT, Lactance et la Bible, París, 1982. 
gica al sexto día de la creación aunque trata de toda la creación de Dios, el autor se concentra especialmente en el aspecto físico de la naturaleza humana, en la anatomía y la fisiología, describiendo el cuerpo a la manera de Aristóteles; también se inspira en el libro II del De natura deorum de Cicerón. Lactancio sigue el plan tradicional de las exposiciones técnicas y científicas sobre el hombre que, desde Aristóteles, va de arriba hacia abajo y de delante hacia detrás: va de la cabeza (cap. 8) y sus órganos a las manos y al tronco (caps. 9-10); a las partes internas (cap. 11) y a los órganos de la concepción (cap. 12), finalmente a los miembros inferiores (cap. 13); si este plan no lo sigue el autor en detalle, es porque su objetivo no es escribir un tratado de anatomía "científica", aunque su fuente médica sea sin duda Galeno ${ }^{42}$.

Por su parte, el obispo Ambrosio de Milán (ca. 329-397, obispo en 374) se configura como el sucesor latino de Lactancio en el género e introduce el Hexameron griego en la literatura latina. Así, la parte final de su homilia sobre los seis días de la creación $(6,61-74)$ está consagrada al hombre siguiendo el esquema bíblico. Ambrosio, que predicó este sermón en 389, se inspira en Cicerón y Lactancio, y aprovecha a Basilio, In Hexaemeron $X, X I$, como modelo exegético. Los temas que desarrolla Ambrosio son los siguientes: la belleza del hombre se debe a su estación erguida $(6,54$ ss.); el hombre es un microcosmos y su cabeza es la parte más importante de su cuerpo ( $6,55 \mathrm{ss}$.); amplia descripción de la cabeza (6, 58 ss.); partes superiores del hombre $(6,69 \mathrm{ss}$.); partes inferiores hasta el diafragma $(6,69-74){ }^{43}$.

Finalmente, la obra de antropología cristiana más conocida a fines del siglo IV o principios del $\mathrm{V}$, construida ampliamente sobre la medicina galénica (fisiología experimental), es el De natura hominis del obispo Nemesio de Emesa, traducida a latín por el arzobispo de Salerno Nicola Alfano en

42 Ver PERRIN, 1974, 24-26, 57.

43 C. SCHENKL, Sancti Ambrosii Opera Pars I, CSEL XXXII/1, Vindobonae, 1897, 251-252; ver TEMKIN, 1991, 134. Ver E. LucchesI, L'usage de Philon dans l'oeuvre exégetique de Saint Ambrose. Une «Quellenforschung" relative aux commentaires d'Ambroise sur la Genèse, Leiden, 1977; L.F. Pizzolato, La dottrina esegetica di sant'Ambrogio, Milano, 1978; H. Savon, Saint Ambrose devant l'exegèse de Philon le Juif, París, 1977; J. PÉPIN. Théologie cosmique et théologie chrétienne (Ambroise, Exam. 1 1, 1.4), París, 1964. La influencia de Lactancio sobre la idea de la importancia de la cabeza en el hombre es clara: "aquellos que están instruidos en el arte de la medicina mantienen, de hecho, que el cerebro está colocado en la cabeza del hombre por motivo de los ojos y que los otros sentidos de nuestros cuerpos están situados muy juntos a causa del cerebro. Éste es la fuente de nuestro sistema nervioso y de todas las sensaciones del movimiento voluntario"; el obispo de Milán también hace del cerebro, "el punto de partida de las arterias y de ese calor natural que da vida y viveza a las partes vitales", aunque añade que "muchos opinan que su punto de partida está en el corazón» (Hexameron 6, 55 ss.). 
el siglo Xi. Se trata del primer tratado sistemático de antropología cristiana y aborda problemas relacionados con la naturaleza del hombre y del alma. Nemesio utiliza tradiciones aristotélicas, estoicas y neoplatónicas, pero sobre todo la obra de Galeno y la exégesis teológica del Comentario al Génesis de Orígenes; los capítulos 4 a 27 están dedicados a la estructura compleja del hombre y al funcionamiento del organismo corporal en relación con las actividades humanas ${ }^{44}$.

5. La última parte del De substantia de Potamio de Lisboa puede considerarse una forma de Hexameron cristiano a nivel de exégesis teológica, no pastoral. La obra es un tratado dogmático en forma de carta, una verdadera disertación teológica sobre la consustancialidad divina que profundiza las argumentaciones ortodoxas de Potamio en su Epistula ad Athanasium ${ }^{45}$. El obispo de Lisboa considera, contra los arrianos, que las Escrituras emplean bien el término substantia y trata de mostrar la doctrina de la consustancialidad por medio de imágenes y símbolos.

Para Tovar, la Epistula de substantia presenta una estructura diferente de los sermones de Potamio: hay un pasaje programático al comienzo y un esquema del discurso, aunque el resultado sea un marcado tono retorizante mediante el recurso de ampliación por congeries. Los referentes léxicos del pasaje programático de la Epistula de substantia remiten a las descripciones anatómicas de los sermones, que para Tovar son solamente un polo del recurso de la synkrisis: secreta legis intrare, medullas dogmatis aurire, viscerum venas adtingere et interna parabolarum membra palpare. Así, el proyecto de estructuración del discurso se basa en el conexum de figuras acerca de la substantia, que asocia las tres personas de la Trinidad; se trata pues de un proceso de acumulación de imágenes para hacer comprender la relación de los extremos del triángulo trinitario ${ }^{46}$.

El tratado desarrolla una treintena de analogías y, en la parte final, Potamio busca la imagen de la Trinidad en el cuerpo del hombre material. Tras una serie de metáforas basadas por lo general en la naturaleza, en los nn. 22-23 del tratado, el obispo de Lisboa pasa a una tercera serie de

44 Edición M. MoRAnI, Leipzig, Teubner, 1987; la edición de la obra de Nicola Alfano en C.J. BuRKHARD, Leipzig, 1917. Sobre Nemesio, ver principalmente E. ESKERD, «Nemesiosstudien l. Nemesios und Genesis-exegese", Symbolae Osioenses 15-16 (1936) 23-43; ID., "Nemesiosstudien II. Nemesios und Galenos", Ibid. 17 (1937) 9-25; ID., "Nemesiosstudien III. Nemesios und die Elementlehre des Galenos», Ibid. 18 (1938) 31-41, ID., "Nemesius d'Émèse», PW Suppl. 7, 1940, 562-566.

45 Sobre el contenido del De substantia ver MONTES MOREIFA, 1969, 232 ss. y 1975, 315, 322-323; Madoz, 1947, 100; Scuderi RugGiefi, 1969, 141-148, con análisis literario de las estructuras sintácticas y del vocabulario.

4E TOVAR, 1994, 103-104. 
comparaciones basadas en el cuerpo humano: a partir de Génesis 1, 26 ("Faciamus hominem ad imaginem et similitudinem nostram"), Potamio trata de descubrir la imagen de Dios uno y trino en los rasgos exteriores del hombre, especialmente en el rostro (Dissona facies, sed uultus aequalis est) ${ }^{47}$. La argumentación de Potamio se basa en la articulación unidad-pluralidad: la unidad de sustancia divina a través de la distinción de elementos físicos (distinción de las personas divinas). Así, con verdadero lujo de pormenores, admira la unidad del semblante del hombre por la concordancia estética de las dos mejillas, expresión de una sola fisonomía (nn. 23 y 29); la unidad de visión a través de la armonía de los dos ojos sabiamente regidos por ocultas riendas ( $\mathrm{nn} .24$ y $26-27$ ); la estrecha colaboración y servicio mutuo de funciones entre los ojos y la nariz $(n, 025)$; la unidad del lenguaje gracias a los movimientos combinados de la lengua y los dos labios ( $\mathrm{n} .{ }^{-028}$ ); la unidad de audición por la hermandad de las dos orejas (n. $\left.{ }^{\circ} 29\right)$. Potamio aprecia también la unidad de la sustancia trinitaria en la sinergia eficaz que hay entre los dos brazos, entre sus tres partes y entre la mano y los dedos; ve, asimismo, en los brazos los dos Testamentos, que, extendidos, proyectan la imagen de la Cruz y, con los dedos de la mano, enumeran los oráculos de la ley de Dios ( $n$ n. 31 y 32).

Potamio trata en esta descripción del hombre los mismos sentidos y funciones del cuerpo resucitado de Lázaro: vista, oído, voz, movimiento de los miembros (anatomía de la vida). Es probable que en esta descripción anatómica (concebida como exégesis teológica) exista una influencia de

47 Nam ut unitas ipsa trinae maiestatis ac nominis ad nostram concurreret notionem, sic ait inuisibilis ipsa maiestas: "Faciamus hominem ad imaginem et similitudinem nostram". Ecce docuit quid credamus. Imaginem suam in hominis uultu signauit et dixit: "ad imaginem nostram". Patris et Fili cognitio in hominis uultu digeritur; et qualis esset Pater et Filius, talem in archetypam humanam de limo quo fingimur caracter sui uultus expressit, ut homo deum ex homine miraretur. Et ne beluae forsitan conparet faciem maiestatis, uultus humanus ostenderet et pietas in homine ex imagine diuinitatis intraret, uoluit uideri se deus qualis esset in forma, cum hominem suum digessit in linea. Vultus domini praefertur in homine ut "bestiis, auibus, pecoribus, piscibus", non homo sed imago potius "imperaret". Merito leo quo nihil fortius in saeculo est, imaginem hominis trepidus expauescit. Vultumque illud quod divinitas suae maiestatis oculauit expinxit timido uultu subducitur ex capite uel fronte sub pectoris indumento celatur. Ergo cum dixit deus: "faciamus hominem ad imaginem et similitudinem nostram", uoluit uideri quid possit, cum in homine qualis esset ostendit. Nostram dixit et unam faciem fabricatus est, ut Patris et Filii hominis liniamenta signaret. Respice igitur de ipsa unitatis effigie qualis possit esse qui fecit, ut omia uultibus nostris sic ordiretur et texeret, ne aliquid despicabile uisui ordinaret, sed gratiae sacra de similitudine speciosa sibiment diuinitas repararet. "Faciamus" inquit "hominem ad imaginem et similitudinem nostram". Et liber Genesis ait: «Et fecit deus hominem ad imaginem dei». Dissona facies, sed uultus aequalis est (PL Suppl 1, vol. 22, París, 1958, cols. 202-216, 210-211). Ver SIMONETI, 1974, 135, para quien estas comparaciones de Potamio llevan a afirmaciones de una neta significación materialista y antropomórfica, a partir de la suposición de que la cara es una imagen real del Dios corporal (Imaginem suam in hominis uultu signavit... Vultus domini praefertur in homine...) 
Lactancio, el inmediato y único predecesor latino de Potamio en el género hexameral, especialmente de su digresión sobre los órganos pares en el cuerpo humano: «Esto nos permite comprender cómo el número dos, constituido por un solo y único conjunto, contribuye a la perfección de las cosas. Pues, aunque el cuerpo sea uno, no podría estar compuesto todo entero de organismos simples sin que hubiera partes izquierdas y derechas. Es por esto que, al igual que los pies y las manos ejercen útilmente las funciones de andar y fabricar, y también confieren al hombre un aspecto y una belleza admirables, de la misma forma en la cabeza, que es por así decirlo la cima de toda la obra divina, el artesano supremo ha repartido el oído en dos orejas, la vista en dos ojos, el olfato en las dos ventanas de la nariz, porque el cerebro, en el que se encuentra el sistema de los sentidos, ha sido separado en dos partes a pesar de su unicidad por una membrana intermedia. Y también el corazón, que parece ser la sede de la sabiduría, a pesar de su unicidad, tiene dos pliegues internos, que contienen las fuentes vivas de la sangre, separados por una barrera mediana: asi pues, al igual que en el mundo incluso el poder soberano - aunque sea doble a partir de lo simple o simple a partir de lo doble-gobierna y contiene la totalidad, de la misma forma en el cuerpo, constituido por elementos dobles, todo el conjunto manifiesta una unidad indisoluble» ${ }^{48}$. En este sentido, no hay que olvidar la breve alusión de Potamio a la estructura doble del cuerpo humano cuando relata el martirio de Isaías: nisi in unum corpus duas offulas gemini paene cadaueris scissae carnis ruptura truculentus appeteret, et duas de aequalitate iuncturae quasi formulas exsecaret.

6. El estilo de las descripciones anatómicas de los sermones de Potamio supone una escritura personal del obispo de Lisboa, más que el reflejo de una cultura literaria regional o la influencia del habla coloquial sobre la lengua escrita. Las descripciones anatómicas tenebristas de Potamio, esa «fisicidad sanguínea», esa "anatomía alucinante» que habla a la vista y a los

${ }_{48}$ De opificio dei 10, 9-11: Ex quo intelligimus quantum dualis numerus una et simplici conpage solidatus ad rerum ualeat perfectionem. Nam cum sit corpus unum, tamen totum ex simplicibus membris constare non poterat, nisi ut essent partes uel dexterae vel sinistrae. Itaque ut pedes duo et item manus non tantum ad utilitatem aliquam usumque uel gradiendi uel faciendi ualent, sed et habitum decoremque admirabilem conferunt, sic in capite, quod totius divini operis quasi culmen est, et auditus in duas aures et uisus in duas acies et odoratio in duas nares a summo artifice diuisa est, quia cerebrum, in quo sentiendi ratio est, quamuis sit unum, tamen in duas partes membrana interueniente discretum est. Sed et cor, quod sapientiae domicilium uidetur, licet sit unum, duos tamen intrinsecus sinus habet, quibus fontes uiui sanguinis continentur saepto intercedente diuisi, ut sicut in ipso mundo summa rerum uel de simplici duplex uel de duplici sim. plex et gubernat et continet totum, ita in corpore de duobus uniuersa conpacta indissociabilem praetenderent unitatem (ed. PERRIN, 1974, I, 160-162). 
sentidos del olfato (Lázaro) y del oído (Isaías), pertenecen a un estilo formal barroco que es característica propia del autor (ninguna de las descripciones aparece en la fuente de referencia, y la de Lázaro será cortada del sermón). Pero también muestran, en cuanto al fondo, una pedagogía médica propia de Potamio, pedagogía médica que aparece normalizada como anatomía de la vida (a la manera del género hexameral) en la exégesis teológica de la parte final del De substantia, y que tiene un paralelo homilético en la anatomía de la vida del cuerpo resucitado de Lázaro.

Así pues, la anatomía tenebrista que aparece en los sermones de Potamio está dentro de la pastoral médica cristiana de los siglos III y IV, gestada en la simbiosis que se produce entre Hipocratismo y cristianismo desde comienzos del Imperio. Aunque, sin duda, su escritura es heterodoxa tanto desde el punto de vista del estilo (barroquismo) como del contenido (anatomía de la muerte). 